\title{
Research on comprehensive evaluation of low carbon economy development level in Huludao city based on entropy method
}

\author{
Yanchu Zhu ${ }^{1}$, Hanlin Mu ${ }^{1, a}$, Ye Duan ${ }^{1}, \mathrm{Nan} \mathrm{Li}^{1}$, Zhaoquan Xue ${ }^{1}$ \\ ${ }^{1}$ Key Laboratory of Ocean Energy Utilization and Energy Conservation of Ministry of Education, \\ Dalian University of Technology, Dalian 116024, China \\ aemail: mhldut@126.com (Hailin Mu)
}

Keywords: entropy method; Low carbon economy development level; Huludao.

\begin{abstract}
Index weight is determined in this paper based on the method of entropy weight, and the evaluation system of the low carbon economy development level on Huludao is built, the comprehensive evaluation index of low carbon economy development level on Huludao is calculated from 2005 to 2014, and the results are ranked according to the relevant standards. The results show that, the index from 0.2880 to 0.7882 by the ultra-high carbon economy rose to a middle high carbon interval which indicate that low carbon construction on Huludao has obtained certain achievement. And then, some concrete suggestions about the low-carbon city construction during the period of "13 ${ }^{\text {th }}$ Five Year Plan" on Huludao are presented.
\end{abstract}

\section{Background}

The condition of China's economic development is undergoing great change, economy is into a new orbit, it is among the Growth phase shift, the structural adjustment of throes and the early stage of the stimulus digestion phase. At present, Liaoning economic development is mainly by "high investment, high energy consumption, high pollution" as the main development pattern, which has an evident character of high carbon. The new situation of global economic development shows that low carbon economy has become a new type economy of world economy-leading. This is an adjustment and reform of economy development method once again after information economy.

Low carbon economy is a new type economic and technological and social system, it has many advantages compared with the traditional economic system. This economic requires us both to save energy, to reduce greenhouse and to have to keep economic and social development in the production and consumption. Low carbon economy can be achieved through technology leapfrog development and institutional constraints, the main behaves as follows, enhance the efficiency of energy, the optimization of energy structure, rational consumer behavior, etc.

Compared with the foreign, domestic scholars' research and study about low carbon level development are limited to the large area such as provincial, or the central city study about important area. Such as $\mathrm{Fu}$ [1], Zhuang [2], etc. preliminary discussed the principle of low carbon economy evaluation index system construction and how to determine the index weight and dimension less the index method. Feng analyzed the low carbon economic index of Hubei, the result is pretty good and show that the overall planning of Hubei is well [3]. Yang used the method of DEA analyzed the efficiency of Sichuan, and on this basis, come up with some countermeasures for the development of low carbon economy [4].Zhang constructed the evaluation index system of Lanzhou low carbon city based on the DPSIR model, show that nowadays Lanzhou is belonged to the interim from high carbon economy transition to ultra-high carbon type [5]. Literature is more, maybe have some certain reference value, but for the heavy industry city main by non-ferrous metal and the shipbuilding, resource-oriented and non-regional hub city. Huludao needs to build up its own low carbon economic development evaluation system, so that to develop a more reasonable direction and the construction of low carbon economy. 


\section{Methodology}

Entropy weight method is the comprehensive evaluation method that can be used for multiple objects and multiple indexes, the entropy is to measure the data provided by the information effectively. The bigger the difference on some indexes of evaluation object, the smaller the entropy value is. The more the effective information provided by the index, the bigger the weight, and vice versa [6].So, the entropy weight method is an objective method, when evaluating urban economy development level, not only the subjective judgment but also the analysis and evidence of the objective data. Therefore, this paper determines the weight of each index by the difference degree of the each index on Huludao, and then analysis the low carbon economy development level.

\section{The model of comprehensive evaluation of development of low carbon economy level}

Synthesizes the availability and the representative of the data, and in combination with the practical situation of Huludao, this paper determines the low carbon economy development level on Huludao by building the model of low carbon economy evaluation index system and selects indexes data from 2005 to 2014 using the entropy weight method. The index system table as follows.

Table 1 The low carbon economy evaluation index system on Huludao

\begin{tabular}{|c|c|c|c|}
\hline $\begin{array}{l}\text { Target level } \\
\text { index }\end{array}$ & First level index & Sub-level index & Direction \\
\hline \multirow{22}{*}{$\begin{array}{c}\text { Low carbon } \\
\text { economy } \\
\text { development } \\
\text { level on Huludao } \\
\text { X }\end{array}$} & \multirow{4}{*}{$\begin{array}{c}\text { Resource Index } \\
\mathrm{Y}_{1}\end{array}$} & $\mathrm{Z}_{1}$ Forest coverage $(\%)$ & \\
\hline & & $\mathrm{Z}_{2}$ Per capita green area $\left(\mathrm{m}^{2} /\right.$ person $)$ & \\
\hline & & $\mathrm{Z}_{3}$ Per capita grassland area $\left(\mathrm{m}^{2} /\right.$ person $)$ & \\
\hline & & $\mathrm{Z}_{4}$ Afforestation area (Hectare) & \\
\hline & \multirow{4}{*}{$\begin{array}{c}\text { Technical Index } \\
\mathrm{Y}_{2}\end{array}$} & $Z_{5}$ General industrial solid waste rate of reusing $(\%)$ & \\
\hline & & $\mathrm{Z}_{6}$ Discharge amount of sulfur dioxide $(\%)$ & Inversion \\
\hline & & $\mathrm{Z}_{7}$ Discharge amount of industrial smoke and dust (Ton) & Inversion \\
\hline & & $\mathrm{Z}_{8}$ Life garbage treatment rate $(\%)$ & \\
\hline & \multirow{6}{*}{$\begin{array}{l}\text { Life index } \\
\mathrm{Y}_{3}\end{array}$} & $\begin{array}{l}Z_{9} \text { The number of the bus per ten thousands of person own } \\
\text { (table) }\end{array}$ & \\
\hline & & $\mathrm{Z}_{10}$ The per capita disposable income of urban $(¥)$ & \\
\hline & & $\mathrm{Z}_{11}$ Housing area per capita of urban $\left(\mathrm{m}^{2}\right)$ & \\
\hline & & $\mathrm{Z}_{12}$ Rural per capita net income $(¥)$ & \\
\hline & & $Z_{13}$ The per-capita living space of village $\left(\mathrm{m}^{2}\right)$ & \\
\hline & & $\mathrm{Z}_{14}$ Urbanization rate $(\%)$ & Inversion \\
\hline & \multirow{4}{*}{ Economic index $\mathrm{Y}_{4}$} & $Z_{15}$ Second industry Per GDP (\%) & Inversion \\
\hline & & $\mathrm{Z}_{16}$ GDP per person $(¥)$ & \\
\hline & & $\begin{array}{c}Z_{17} \text { The proportion of income of Energy saving by fiscal } \\
\text { of local }(\%)\end{array}$ & \\
\hline & & $\begin{array}{c}\mathrm{Z}_{18} \text { The capital expense of urban construction and } \\
\text { maintenance projects }(10000 ¥)\end{array}$ & \\
\hline & \multirow{4}{*}{$\begin{array}{l}\text { The index of energy } \\
\text { consumption and } \\
\text { carbon emission } \mathrm{Y}_{5}\end{array}$} & $\mathrm{Z}_{19}$ Per capita energy consumption $($ Ton $)$ & Inversion \\
\hline & & $\mathrm{Z}_{20}$ Per capita discharge amount of carbon dioxide (Ton) & Inversion \\
\hline & & $\begin{array}{c}\mathrm{Z}_{21} \text { Intensity of carbon dioxide about industrial } \\
(\text { Ton/10000¥ })\end{array}$ & Inversion \\
\hline & & $\mathrm{Z}_{22}$ Energy consumption elasticity coefficient & Inversion \\
\hline
\end{tabular}

\section{The annotation of each index}

Because the forest, public green space, the grass can absorb carbon dioxide, release oxygen, and clean the air. In this research, the select of resource index tends to the carbon sequestration of the green vegetation. At the same time consider the per capita level of the index can reflect the actual 
level of Huludao more. The higher per capita carbon sequestration and Forest coverage, the smaller press of carbon absorbtion, the result is all good for the development of low carbon.

Technical Index refers to the measure of technical about environment for reduce carbon emissions. Life garbage treatment rate and industrial solid waste rate of reusing, respectively, reflect the level of garbage innocent disposal, waste recycling and economic benefit that is advantageous to the low carbon technology innovation. So, the bigger the ratio is, the better the result is, it's belong to the positive index. Industrial discharge amount of sulfur dioxide and Discharge amount of industrial smoke and dust reflect the level of industrial pollutants, and reflect the environmental standards. The lower the emissions, the higher the level, so they're belong to the inverse indexes.

Life index reflect the level of the living standards of the area town and rural, the higher the Per capita living standards is, the more reasonable the energy consumption level tends to be. The per capita disposable income of urban refers to the part of the household all cash income that can use for the family daily life. Urbanization rate used to reflect the process and degree of assembles of the population to the urban.

Economic index reflects the development of the area's economy, the degree of investment and emphasis for environmental. Capital expense of urban construction and maintenance projects refers to the investment use for maintain the infrastructure construction among the urban construction. Obviously, the index is conducive to that the carbon emissions tend to reduce. The industrial structure refers to the proportion of Primary, Second and tertiary industry by GDP.

The index of energy consumption and carbon emission directly reflects the situation of the carbon dioxide of the energy consumption and the fossil fuel burning on one area. The index of energy consumption and carbon emission includes Per capita energy consumption $\left(Z_{19}\right)$, Per capita discharge amount of carbon dioxide $\left(Z_{20}\right)$, Intensity of carbon dioxide about industrial $\left(Z_{21}\right)$, Energy consumption elasticity coefficient $\left(Z_{22}\right)$. Obviously, the indexes are the reverse indicators index.

\section{Sources of data}

According to the principle of the comparability and scientific, the data mainly comes from the annual economic and energy figures released by the government, such as, "Statistical yearbook of the Huludao", "Statistics bulletin of the national economy and social development of the Huludao", etc. In addition, some indexes cannot be received indirectly and they need to be calculated.

\section{Index data processing}

In order to make the results more scientific, these data need to be reverse logistics and dimension, which is conducive to apply and analyze the results.

(1) The indicators of positive transformation. To reverse indicators and make it positive used the reciprocal transformed method.

(2) Dimensionless of index. In order to be easy to compare, make the index dimensionless, keep the all data having the same dimension, adopt the equation.

$$
z_{t}=\left(X_{t}-X_{\min }\right) /\left(X_{\max }-X_{\min }\right) \text {. }
$$

Where, $Z_{i}$ refers to the standardized value; $X_{\bar{i}}$ refers to the original value; $X_{\text {min }}$ refers to the minimum of the data; ${ }^{Z_{\max }}$ refers to the maximum of the data.

\section{The index calculation}

When the number of the index is $\mathrm{m}$, the number of objects which is evaluated is $\mathrm{n}$, then the ith entropy is defined as the follow, 


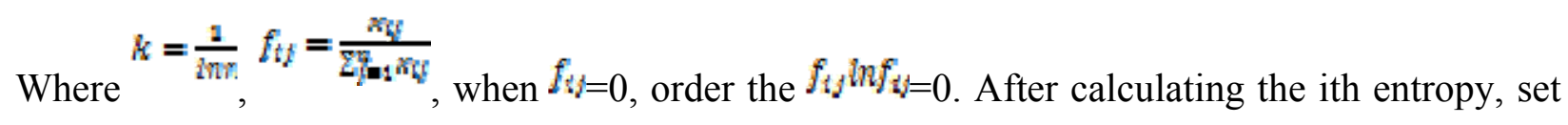
the entropy weight $w_{i}$ to the ith evaluation index, and according to the follow equation to calculate the index weights. The results are shown in Table 2.

$$
w_{t}=\frac{1-\varepsilon_{t}}{n-\sum_{t=1}^{n} e_{t}}
$$

Table 2 Index weight of the low carbon economy development level on Huludao.

\begin{tabular}{|c|c|c|c|c|c|c|}
\hline \multirow{2}{*}{$\begin{array}{c}\text { Index } \\
\text { hierarchy }\end{array}$} & $\mathrm{Y}_{1}$ & $\mathrm{Y}_{2}$ & $\mathrm{Y}_{3}$ & $\mathrm{Y}_{4}$ & $\mathrm{Y}_{5}$ & \multirow{2}{*}{$\mathrm{X}$} \\
\hline & 0.2885 & 0.1025 & 0.2274 & 0.1905 & 0.1911 & \\
\hline $\mathrm{Z}_{1}$ & 0.1971 & & & & & 0.0569 \\
\hline $\mathrm{Z}_{2}$ & 0.2761 & & & & & 0.0796 \\
\hline$Z_{3}$ & 0.1953 & & & & & 0.0563 \\
\hline$Z_{4}$ & 0.3315 & & & & & 0.0956 \\
\hline $\mathrm{Z}_{5}$ & & 0.2638 & & & & 0.0270 \\
\hline$Z_{6}$ & & 0.2282 & & & & 0.0234 \\
\hline$Z_{7}$ & & 0.2527 & & & & 0.0259 \\
\hline $\mathrm{Z}_{8}$ & & 0.2554 & & & & 0.0262 \\
\hline $\mathrm{Z}_{9}$ & & & 0.0945 & & & 0.0215 \\
\hline $\mathrm{Z}_{10}$ & & & 0.1596 & & & 0.0363 \\
\hline$Z_{11}$ & & & 0.1519 & & & 0.0345 \\
\hline$Z_{12}$ & & & 0.2008 & & & 0.0457 \\
\hline$Z_{13}$ & & & 0.1089 & & & 0.0248 \\
\hline$Z_{14}$ & & & 0.2843 & & & 0.0646 \\
\hline $\mathrm{Z}_{15}$ & & & & 0.2521 & & 0.0480 \\
\hline$Z_{16}$ & & & & 0.2486 & & 0.0474 \\
\hline$Z_{17}$ & & & & 0.1483 & & 0.0283 \\
\hline $\mathrm{Z}_{18}$ & & & & 0.3509 & & 0.0669 \\
\hline$Z_{19}$ & & & & & 0.1170 & 0.0224 \\
\hline $\mathrm{Z}_{20}$ & & & & & 0.0864 & 0.0165 \\
\hline $\mathrm{Z}_{21}$ & & & & & 0.2333 & 0.0446 \\
\hline$Z_{22}$ & & & & & 0.5633 & 0.1076 \\
\hline
\end{tabular}

From the table the most important of the factor that influence the development of the low carbon city is Resource Index, because the forest, grass, green space, carbon sink greatly reduce the carbon dioxide, and as a resource-based city, the low carbon city development is closely related to the resource development. It also directly reflects on the Afforestation area $\left(\mathrm{Z}_{4}\right)$.

Secondly, with the progress of the living standard and the education level, people pay more and more attention on the environmental pollution and greenhouse gases. At the same time, the improvement of the living level can change the energy structure, the structure of the trip, technology using trends, etc. It also indirectly has an effect on the development of low carbon city. Where the weighting of each index is uniform, the weight of the urbanization rate $\left(Z_{14}\right)$ is maximal.

Thirdly, energy consumption, carbon emissions index and the economy index, both are important factor of influence of the low carbon development. Because the Huludao is still in a high level of economic growth range with the petrochemical industry, non-ferrous metal, shipping machinery and energy power four pillar industries. The fossil energy consumption caused by the heavy industry, drives the rapid economy development, and the carbon emissions seriously influence the residents' 
life and the environment. Lots of the enterprises are the labor-intensive, resource dependence, energy consumption. Although these enterprises have brought the growth value, the contradiction among the economic development, shortage of energy resources and fragile ecological environment is aggravated. It also reflects on the high weight of index of the economic and energy consumption.

In addition, the technical indexes are also occupy a certain weight, in the case of the attention of structural adjustment, it's also a measure that energy saving and low carbon of the technology. And under the condition of the structure adjustment resistance, a technology innovation will play a key role on construction of low carbon.

In order to calculate the low carbon development level. Firstly, calculate the score of the each single index. Secondly make sure the standard value of each index. Lastly, adding the all scores of the same year. Then obtain the comprehensive index of the low carbon development of that year.

The calculation process can be expressed as: Single index score $=$ weight $\times$ standard values

The calculation of each annual comprehensive index process can be expressed by the follow equation:

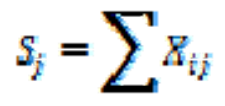

Where, $i=1,2,3 \cdots 22 ; j=1,2 \cdots 10$. i refers to the specific index of the low carbon city of the Huludao. $\mathrm{j}$ refers to the year, it from the year 2005 to the year 2014 .

Through the equation we can calculate the each comprehensive index of the low carbon development of the year from 2005 to the year 2014 on Huludao as follow.

Table 3 Low carbon development level index in 2005-2014 on Huludao

\begin{tabular}{c|c|c|c|c|c}
\hline \multirow{2}{*}{ Low carbon comprehensive index evaluation on Huludao } & 2005 & 2006 & 2007 & 2008 & 2009 \\
\cline { 2 - 5 } & 0.2880 & 0.2707 & 0.3329 & 0.5820 & 0.5419 \\
\hline Resource Index $\mathrm{Y}_{1}$ & 0.0601 & 0.0593 & 0.0326 & 0.0258 & 0.0281 \\
\hline Technical Index $\mathrm{Y}_{2}$ & 0.0722 & 0.0952 & 0.1213 & 0.1969 & 0.2154 \\
\hline Life index $\mathrm{Y}_{3}$ & 0.0838 & 0.0818 & 0.1065 & 0.1135 & 0.1137 \\
\hline Economic Index $\mathrm{Y}_{4}$ & 0.0335 & 0.0098 & 0.0345 & 0.0973 & 0.0915 \\
\hline The index of energy consumption and carbon emission $\mathrm{Y}_{5}$ & 0.0384 & 0.0246 & 0.0380 & 0.1484 & 0.0931 \\
\hline \multirow{2}{*}{ Low carbon comprehensive index evaluation on Huludao } & 2010 & 2011 & 2012 & 2013 & 2014 \\
\cline { 2 - 5 } & 0.5380 & 0.5207 & 0.7067 & 0.7023 & 0.7882 \\
\hline Resource Index $\mathrm{Y}_{1}$ & 0.0919 & 0.1171 & 0.2140 & 0.1422 & 0.1556 \\
\hline Technical Index $\mathrm{Y}_{2}$ & 0.2114 & 0.1627 & 0.1688 & 0.1839 & 0.2241 \\
\hline Life index $\mathrm{Y}_{3}$ & 0.1097 & 0.1294 & 0.1513 & 0.1267 & 0.1479 \\
\hline Economic Index $\mathrm{Y}_{4}$ & 0.0721 & 0.0814 & 0.0812 & 0.1762 & 0.1603 \\
\hline The index of energy consumption and carbon emission $\mathrm{Y}_{5}$ & 0.0529 & 0.0302 & 0.0914 & 0.0732 & 0.1004 \\
\hline
\end{tabular}

From the figure we can know that, compared with the year of the 2005, the low carbon comprehensive evaluation target level index and the first level index are raised in 2014. But it didn't rise all the time, it's usually went up after dropping. For target index as an example, it's in a rising trend from 2006 to 2008, show that low carbon development towards good direction. But from 2009 to 2011 , there was a little decline, it shows that the low carbon level towards the direction of deterioration, and it turned better after 2011, and began to recover, and arrived the maximum in 2014. The curve is same as the energy consumption curve and the economic curve from the past of the decade. This is because the energy consumption arriveed the peak in 2011, while the energy conversion efficiency of processing reacheed the valley, under the various factors, these indexes values were almost the lowest in nearly five years. Similarly, each first level index also presents the fluctuation type growth, after a slight drop from 2009 to 2011, and arrive the maximum value in 2014. In proportion, technical index and life index occupy larger proportion. 
Reference to domestic scholars Ma, Zhou[7], according to the result of the above calculation, from 2005 to 2007, Huludao is during the ultra-high carbon level, and rise later, in 2008, Huludao entered the middle high carbon level and keeping the level, but it declines a bit from the 2008 to 2011, then it rose in 2012. Nowadays, Huludao is in the middle high carbon economic range. It's about 2.9 times to 2006, the minimum. Because in 2010, Liaoning become the first areas of the low carbon, when maintain economic growth, paid more attention to the greenhouse gas emissions and pollution, so the low carbon development level of the Huludao is maintain rising since 2011. This suggests that there are some certain results in the low carbon development of Huludao, at the same time, it greatly accelerates the economic development. According to the current trend of development, Huludao will be into the middle carbon economy in 2016, and it will be into the middle low carbon economy at the end of the "13th Five year plan".

\section{Conclusions and Recommendations}

In this paper, the low carbon economy in the past 10 years of the Huludao was evaluated by using the entropy weigh method, the level of the low carbon economic development and the development trend in the future from the perspective of five indicators were analyzed. In the past decade of the "11th five-year" and "12th five-year", the low carbon development level Huludao has been improved obviously, but it is undeniable that there are ups and downs in the progress of the development. In the "13th five-year plan", the press of our country and Liaoning province is still big, the difficult and the challenge is unprecedented, at the same time the quality of the economic development and the benefit still is not high, the lack of the economic growth and the economic structure are unreasonable. The ecological environment pressure is bigger. The task of the energy conservation and emissions reduction is still heavy.

From the perspective of the current development, the low carbon economic of the Huludao need to develop the circular economic, make the development planning scientific, arrangement the industry development reasonable, gradually reduce the weight of the high carbon industry especially the heavy industry, strengthen the requirements of the low carbon industry, implement the low carbon production. For specific engineering, strengthen protection and management of the coastline. Build the Longxing national wetland park. Carry out the gas haze special projects, control the air pollution, dust pollution and mobile source pollution, promote upgrading coal fired boiler, eliminated the town old boiler $\mathrm{s}$ of below 10 ton, promote the new energy vehicles and implement new bus "greening".Support key enterprises to implement technical innovation of energy conservation and environmental protection, promoting the projects of Jinxi petrochemical waste hydrogen energy utilizations. Encourage public participation in the environmental protection enterprise, form the government corporate social work system of environmental governance.

\section{Acknowledgements}

The authors gratefully acknowledge the financial support from the National Natural Science Foundation of China (71273039). This research has also been supported by the Fundamental Research Funds for the Central Universities (DUT14RC(3)151) and China Postdoctoral Science Foundation (2015M571309).

\section{References}

[1].Fu Jiafeng, Zhuang Guiyang, Gao Qingxian. Conceptual Identification and Evaluation Index System for Low-Carbon Economy [J]. China Population, Resources and Environment.2010, 20(8):38-43.

[2].Zhuang Guiyang, Pan Jiahua, Zhu Shouxian. The Concept of Low-Carbon Economy and the Construction of Evaluation Index System [J]. Economic Perspectives, 2011, (1):132-136. 
[3].Feng Bimei. Study on the Construction of Low-carbon Economy Evaluation in Hubei Province [J]. China Population, Resources and Environment. 2011, 21(3), 54-58.

[4].Yang Ying. Research on evaluation of Sichuan Low-carbon Economy Efficiency [J]. China Population, Resources and Environment.2012, 22(6):52-56.

[5].Zhang Xiaoping, Liu Jing, Fang Ting, Evaluation on the low carbon city development of Lanzhou City based on DPSIR model. Journal of Northwest Normal University (Natural Science) [J].2012, 48(1), 112-115.

[6].ZouZhihong, Sun Jingnan, Ren Guangping. Study and Application on the Entropy method for Determination of Weight of evaluating indicators in Fuzzy Synthetic Evaluation for Water Quality Assessment [J].Acta Scientiae Circumstantiae, 2005, 25(4):552-556.

[7].Ma Jun, Zhou Lin, Li Wei. Indicator System Construction for Urban Low Carbon Economy Development [J].Science and Technology Progress and Policy. 2010, 27 (22) , 165-167. 